Nonlinear Processes in Geophysics (2002) 9: 51-59

Nonlinear Processes

in Geophysics

(C)European Geophysical Society 2002

\title{
Prevention of destructive tropical and extratropical storms, hurricanes, tornadoes, dangerous thunderstorms, and catastrophic floods
}

\author{
E. Yu. Krasilnikov \\ R/D Center of Computer Aided Design, Russian Academy of Sciences, Odintsovo, Moscow Region, Russia
}

Received: 19 March 2001 - Revised: 10 October 2001 - Accepted: 16 October 2001

\begin{abstract}
Tropical cyclones and storms, hurricanes, powerful thunderclouds, which generate tornadoes, destructive extratropical cyclones, which result in catastrophic floods, are the powerful cloud systems that contain huge amount of water. According to the hypothesis argued in this paper, an electric field coupled with powerful clouds and electric forces play a cardinal role in supporting this huge mass of water at a high altitude in the troposphere and in the instability of powerful clouds sometimes during rather a long time duration. Based on this hypothesis, a highly effective method of volume electric charge neutralization of powerful clouds is proposed. It results in the decrease in an electric field, a sudden increase in precipitation, and subsequent degradation of powerful clouds. This method, based on the natural phenomenon, ensures the prevention of the intensification of tropical and extratropical cyclones and their transition to the storm and hurricane (typhoon) stages, which makes it possible to avoid catastrophic floods. It also ensures the suppression of severe thunderclouds, which, in turn, eliminates the development of dangerous thunderstorms and the possibility of the emergence and intensification of tornadoes.
\end{abstract}

\section{Introduction}

Destructive tropical storms, hurricanes (in the Atlantic Ocean), typhoons (in the Pacific Ocean), tornadoes, severe thunderstorms, and extratropical cyclones and storms result in catastrophic floods, death and injury, and result in huge material damage in many countries. Here are several examples. On 22-27 August 1992, the Hurricane Andrew, with a wind speed up to $280 \mathrm{~km}$ per hour, passed over the Bahamas, southern Florida and Louisiana, causing improbable destruction. "Andrew's legacy is appalling: 62 dead, 160000 homeless, property damage estimated at $\$ 30$ billion..." (Becker, 1993). The total number of deaths attributed to the devas-

Correspondence to: E. Yu. Krasilnikov

(tor-nado@mtu-net.ru) tating Hurricane Mitch, a category 5 monster with a wind of more than $320 \mathrm{~km}$ per hour, during its two weeks of life (21 October-5 November 1998) is estimated at 11000 . It also resulted in huge damage in the Central American countries of Honduras, Guatemala, Nicaragua.

In addition, up to 2000 tornadoes are observed annually on the Earth. More than half make land fall in the United States. The most fearful example is the Tri-State Tornado on 18 March 1925 that passed along southern Missouri, southern Illinois, and southwest Indiana, and killed 698 people. Severe thunderstorms also present a serious problem since they result in deaths from lightning, fires, aircraft crashes, power plant damages, and so on. The destruction and the large number of deaths are caused annually by catastrophic floods brought about by abundant and long-lasting rains, drenching continents, and from oceans brought about powerful extratropical cyclones and storms. The catastrophic flood of July-August 1993 in the midwestern United States claimed 40 lives, and the cumulative damage was $\$ 45$ billion. In July-August 1997, much more damage was caused by the catastrophic flood in Europe (especially in Germany, Poland, and the Czech Republic). In October-December 2000, the destructive extratropical cyclones and storms resulted in devastating floods, deaths, and huge damage in England, France, Germany, Portugal, Spain, and other countries in Europe.

The previous examples show that these awful phenomena result annually in thousands of deaths, destruction, and damage in excess of billions of dollars. A legitimate question is whether there is a possibility to prevent the beginnings and formation of tornadoes, the intensification of tropical cyclones, and to facilitate their transfer to the storm and hurricane stages, and to suppress dangerous thunderstorms. The answer from the author's point of view must be undoubtedly positive. But in order to develop an effective method and means for the prevention of these destructive phenomena, scientists must completely understand their physical nature. Thus, a specific question is in order: "Is there a definite understanding by the scientists concerning the physical nature of intense atmospheric vortices (tropi- 


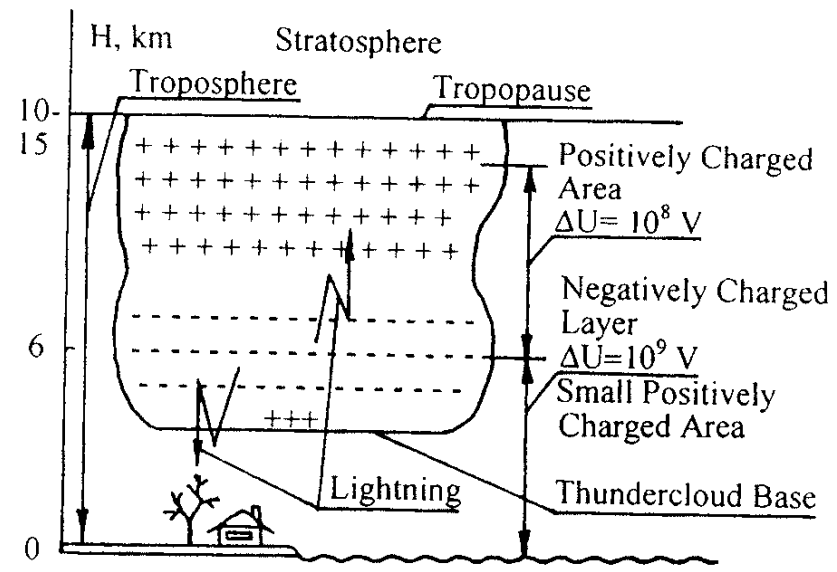

Fig. 1. Scheme of a single mature thundercloud cell.

cal cyclones, hurricanes, and tornadoes)?" The answer has been given by the leading scientists working in this field. Here are several of their affirmations. Ooyama (1982), "At times, communication among investigators has seemed to have presented as difficult a problem as the tropical cyclone itself. Some views of the theoretical progress are misleading"; Davies-Jones (1995), "The storms that spawn twisters are now largely understood, but mysteries still remain about how these violent vortices form." and "we have yet to pin down why tornadoes are the result of surface friction. This observation seems paradoxical because friction generally reduces wind speeds"; Snow (1984), "In spite of such recent advances, understanding of tornadoes remains in some ways quite limited. There also seem to be several other processes that can yield the concentration of spin needed to generate a tornado, and the details of these mechanisms and the relations among them remain puzzling.". In order to describe the intensification of tropical cyclones and tornadoes, many completely different models have been proposed which are based on principally different physical processes. Evidently, there is a doubt about the adequacy of the models proposed since all of them still describe one and the same phenomenon. Moreover, they all contradict the observational data. For example, according to Snow (1984), "Tornadoes form in the updrafts of thunderstorms", and DaviesJones (1995), "A region of updraft one to three miles in radius may begin to rotate with wind speeds of 50 miles per hour or more, forming a mesocyclone. The storm may then develop low-level rotation and even a tornado". At the same time, they assert, "Doppler radar observations have shown that the rotation begins in the mid-troposphere, at altitudes of four to eight kilometers. Once the rotation has begun at midlevels, it builds down toward the ground" (Snow, 1984), and "the first Doppler measurements were confirmed in 1971. This circulation, first apparent at a height of about three miles, is followed by rotation at much lower levels, preceding the development of any intense tornado" (Davies-Jones, 1995). Here, another question is in order: "Which assertion is correct?" These contradictory statements reflect the current condition of the understanding of the physical nature of intense atmospheric vortices. From the author's point of view, this nebulous situation has quite an explainable basis.

It may be a paradox, but contemporary meteorology has been divided in two completely detached parts. The first one is "traditional meteorology" which analyzes the intensification processes of tropical cyclones and tornadoes (and other processes in the troposphere) considering thermodynamic and hydrodynamic processes only. The second part is the electrophysics of the troposphere and the electric features of clouds. It is very surprising, but the first part does not consider nor account for the occasional abnormal electric features of powerful clouds and the processes caused by the action of strong electric fields coupled with the clouds. So, for example, the maximum electric potential gradient in thunderclouds reaches $1.5 \times 10^{6} \mathrm{~V} / \mathrm{m}$ (Chalmers, 1967). At this value, $1 \mathrm{~m}^{3}$ of air containing water drops and ice crystals with an electric charge density $\rho=5 \times 10^{-5} \mathrm{~cm}^{-3}$ at the height of $5 \mathrm{~km}$ has the acceleration (e.g. directed downward) of $a=97.4 \mathrm{~ms}^{-2}$. The total electric charge (of any sign) of an average sized hurricane amounts to $10^{10} \mathrm{C}$, which is more than 17000 times as large as the Earth's total electric charge (Krasilnikov, 1997). These abnormal electrical properties are obviously observed nowhere else in the Earth's nature. Thus, electric and electromagnetic forces could be greater than all other forces. This circumstance completely eliminates the possibility of an understanding of physical nature with respect to the processes that stipulate the intensification of tropical and extratropical cyclones and tornadoes. This, in turn, rules out the possibility of any adequate physical and mathematical model development. To confirm the aforementioned discrepancy, one notably expository example is considered further. According to the concept accepted in traditional meteorology, during the formation of any powerful cloud, the temperature of the moist air lifted upwards from the ocean (sea, lake) surface changes adiabatically. The measurement data of the air temperature in the upper part of the powerful clouds have shown that it is much lower than the temperature calculated in conformity with the adiabatic process. For an explanation of this discrepancy, a hypothesis has been accepted about entrainment of dry and cold air from the cloud environment that ostensibly absorbs the thermal energy, thereby reducing the temperature of the warm moist air (Sedunov et al., 1991). However, during the formation of any cloud, an electric field coupled with it appears and strengthens as the cloud increases. The electric field energy of a mature thundercloud (Fig. 1) with the electric charge (of any sign) $q=1400 \mathrm{C}$ (Wormel, 1953) amounts to $\mathrm{W}_{E} \approx 10^{12} \mathrm{~J}$. Where has this energy come from? Undoubtedly, this energy is subtracted from the energy released in the process of vapor condensation and in the transition of water drops to ice crystals in a cloud. This is indeed the real and only cause that explains the aforementioned temperature discrepancy.

Consequently, a hypothesis is proposed that an electric field coupled with powerful clouds plays a cardinal role in their formation and stability. Based on this theory, an effective method of the neutralization of a volume electric charge 
Table 1. Comparison of electric force and gravity

\begin{tabular}{cccccc}
\hline$r, \mathrm{~mm}$ & $q, \mathrm{C}$ & $E, \mathrm{~V} / \mathrm{m}$ & $\mathrm{mg}, \mathrm{N}$ (water) & $\mathrm{mg}, \mathrm{N}$ (ice) & $F_{E}, \mathrm{~N}$ \\
\hline 1.5 & $2.25 \times 10^{-9}$ & $10^{6}$ & $1.39 \times 10^{-4}$ & $1.27 \times 10^{-4}$ & $2.25 \times 10^{-3}$ \\
1.0 & $10^{-9}$ & $10^{5}$ & $4.11 \times 10^{-5}$ & $3.77 \times 10^{-5}$ & $10^{-4}$ \\
0.5 & $2.5 \times 10^{-11}$ & $5 \times 10^{4}$ & $5.14 \times 10^{-6}$ & $4.71 \times 10^{-6}$ & $1.25 \times 10^{-5}$ \\
0.1 & $10^{-11}$ & $5 \times 10^{3}$ & $4.11 \times 10^{-8}$ & $3.77 \times 10^{-8}$ & $5 \times 10^{-8}$ \\
0.05 & $2.5 \times 10^{-12}$ & $2.5 \times 10^{3}$ & $5.14 \times 10^{-9}$ & $4.71 \times 10^{-9}$ & $6.25 \times 10^{-9}$ \\
0.01 & $10^{-13}$ & $2 \times 10^{2}$ & $4.11 \times 10^{-11}$ & $5 \times 10^{-11}$ & $3.77 \times 10^{-8}$ \\
\hline
\end{tabular}

$r$ is the particle radius; $q$ is the particle electric charge;

$E$ is the electric field strength; $F_{E}$ is the electric force directed vertically upward.

of powerful clouds is suggested. This method, based on the natural phenomenon, ensures the prevention of the intensification of tropical and extratropical cyclones and their transition to the storm and hurricane (typhoon) stages, which makes it possible to avoid catastrophic floods. In addition, it ensures the suppression of severe thunderclouds, which, in turn, eliminates the development of dangerous thunderstorms and the possibility of the emergence and intensification of tornadoes.

\section{Action of electric forces in clouds}

The electric field in the Earth's atmosphere is known to exist in the absence of clouds. At an altitude of $6 \mathrm{~km}$, the electric potential reaches $2.2 \times 10^{5} \mathrm{~V}$ (Clark, 1957). However, during the arising and increasing of any cloud, an electric field coupled with it is formed and strengthened. Many studies have been conducted into the nature of this electric field. This problem includes three main aspects. The first two are related to the processes of the formation and separation of electric charges in the clouds. In spite of extensive and prolonged studies (Chalmers, 1967; Workman, 1950; Vonnegut, 1953), there is still no common viewpoint with respect to the mechanism of electric charge formation during cloud formation and with respect to the process of their separation. However, numerous studies of the third aspect show that the electric structure of a mature thundercloud (Fig. 1) is the tripole one (Chalmers, 1967; Williams, 1989; Byrne et al., 1989). At an altitude of about $6 \mathrm{~km}$ (according to different authors, the range is from 3 to $8 \mathrm{~km}$; Chalmers, 1967) above the Earth's surface, where the air temperature is about $-15^{\circ} \mathrm{C}$, there is the center of the negatively charged layer. Its height, as a rule, does not exceed $1 \mathrm{~km}$. The positively charged area occupies the upper part of a thundercloud. The third small positively charged area is placed in the very lower part of a thundercloud (the reason for its formation is not established yet). The Earth's surface under a thundercloud has an induced positive charge. The potential difference between the negatively charged layer and the ground surface is $10^{9} \mathrm{~V}$, and between the negatively charged layer and the top part of a thunder- cloud (Fig. 1) is $10^{8} \mathrm{~V}$ (Shonland, 1964). Inside a thundercloud, the largest values of the electric potential gradient are located at the upper and caudal boundaries of the negatively charged layer and change from $1.5 \times 10^{5}$ to $2 \times 10^{6} \mathrm{~V} / \mathrm{m}$ (Norinder and Salka, 1951; Imianitov et al., 1971; Ziegler and MacGorman, 1994; Marshall and Rust, 1995). These values correspond to the conditions where lightning takes place. Data of measurements and estimates of the maximum volume electric charge density in thunderclouds attain values in the range of $10^{-9}-10^{-4} \mathrm{~cm}^{-3}$ (Byrne et al., 1989; Imianitov et al., 1971; Ziegler and MacGorman, 1994; Matveev, 1984). It should be noted that measurement data about the electric features of clouds in tornadoes and hurricanes are completely absent. Powerful clouds contain a huge amount of water in the form of drops, vapor, and ice crystals. For instance, according to Riehl (1979), the volume of water absorbed in a hurricane of an average size with the radius $R \sim 500 \mathrm{~km}$ from the ocean's surface per day amounts to $16 \mathrm{~km}^{3}$, which is equivalent to the Colorado River's annual runoff. This corresponds to the mass of water equal to 16 billion tons per day and the overall hurricane's water mass reaches $10^{12}$ tons. The apparent question follows: "What forces support this huge mass of water at a high altitude in the troposphere?" The answer is obvious, "It is the force of an electric field coupled with powerful clouds".

The aforementioned values correspond to powerful thunderclouds. From the author's point of view, the role that an electric field plays in the formation, development, and stability of powerful clouds to date has not been understood. In connection with this, a hypothesis is proposed here: any cloud can exist only if there is an enough of a strong electric field coupled with it. Herewith, the electric field strength increases proportionally to a cloud capacity. The main force supporting a huge mass of water in powerful clouds (in the form of vapor, drops, and ice crystals) at a high altitude in the troposphere is the force of an electric field directed vertically upward. This force ensures the stability of any cloud which can last for a long time. In addition, in the negatively charged layer and the positively charged area, the repulsive (Coulomb) force acts, which, in turn, prevents the development of the coagulation process which, in turn, conduces the 
Table 2. Estimation of vertical wind

\begin{tabular}{cccccccc}
\hline $\begin{array}{c}r \\
\mathrm{~mm}\end{array}$ & $\begin{array}{c}H \\
\mathrm{~km}\end{array}$ & $\begin{array}{c}T \\
\mathrm{~K}\end{array}$ & $\begin{array}{c}\rho_{\text {air }} \\
\mathrm{kgm}^{-3}\end{array}$ & $\begin{array}{c}v \times 10^{-4} \\
\mathrm{~m}^{2} \mathrm{~s}^{-1}\end{array}$ & $c_{w}$ & $R e_{d}$ & $\begin{array}{c}w_{\text {vert }} \\
\mathrm{m} / \mathrm{s}\end{array}$ \\
\hline 0.25 & 5 & 256 & 0.736 & 0.221 & 1.4 & 57.0 & 2.52 \\
0.25 & 10 & 223 & 0.414 & 0.351 & 1.75 & 42.8 & 3.0 \\
0.25 & 15 & 219 & 0.2 & 1.250 & 3.2 & 12.8 & 3.2 \\
0.5 & 5 & 256 & 0.736 & 0.221 & 0.8 & 213.2 & 4.7 \\
0.5 & 10 & 223 & 0.414 & 0.351 & 0.82 & 176.6 & 6.2 \\
0.5 & 15 & 219 & 0.2 & 1.250 & 1.5 & 52.8 & 6.6 \\
1.0 & 5 & 256 & 0.736 & 0.221 & 0.52 & 748.0 & 8.27 \\
1.0 & 10 & 223 & 0.414 & 0.351 & 0.53 & 622.2 & 10.9 \\
1.0 & 15 & 219 & 0.2 & 1.250 & 0.775 & 207.9 & 13.0 \\
1.5 & 5 & 256 & 0.736 & 0.221 & 0.395 & 1577.2 & 11.5 \\
1.5 & 10 & 223 & 0.414 & 0.351 & 0.395 & 1324.8 & 15.5 \\
1.5 & 15 & 219 & 0.2 & 1.250 & 0.54 & 457.5 & 19.1 \\
\hline
\end{tabular}

$r$ is the drop's radius; $H$ is the height in the troposphere; $T$ and $\rho_{\text {air }}$ are the temperature and air density at the height $H$; $v$ is kinematic viscosity; $c_{w}$ is the resistance coefficient; $R e$ is the Reynolds number; $w_{v e r t}$ is the vertical wind speed.

stability of the clouds as well.

To confirm the hypothesis proposed here, the comparison of an electric force $\boldsymbol{F}_{\boldsymbol{E}}$ and the gravity $\boldsymbol{m} \boldsymbol{g}$ acting on particles in the clouds is presented (Table 1). The calculated values are based on measurement data of particle charges in the clouds (Gunn, 1947, 1950; Smith, 1955; Phillips and Kinzer, 1958), which gives the values in the range of $q=10^{-13}-10^{-9} \mathrm{C}$. The particles with a radius of $r=1 \mathrm{~mm}$ may exist at the electric field strength of $E=10^{5} \mathrm{~V} / \mathrm{m}$ in Nimbostratus and Cumulonimbus. However, higher values of the potential gradient of an electric field and, therefore, of the force $\boldsymbol{F}_{\boldsymbol{E}}$ may exist in thunderclouds. The smallest particles with $r=0.01 \mathrm{~mm}$ that exist at $E=5.0 \times 10^{2} \mathrm{~V} / \mathrm{m}$ correspond to conditions at the initial stage of the cloud formation or in small clouds.

It should be noted that according to the conventional viewpoint in meteorology, the abnormal mass of water in powerful clouds is supported at a high altitude in the troposphere only by updrafts rising upwards from the ocean and ground surface. Herewith, any powerful cloud from its emergence, up to its degradation, passes through three development stages. At the initial stage, updrafts dominate. The second stage is a period of cloud maturity, in which updrafts play a dominant role, but downdrafts appear as well. In the third stage, when degradation takes place, downdrafts dominate. This representation from the author's point of view is incorrect, in principle. In fact, at the initial stage, updrafts play the dominant role in the formation of clouds. But from the appearance of any cloud, an electric field coupled with it is formed and strengthened, along with an increase in cloud capacity and plays a cardinal role in the stability of clouds.
As for the stage of maturity, the role of updrafts is not essential and, a fortiori, determinant. For the stability of powerful clouds at this stage, only the forces of the electric field have the main significance and the electric field determines the cloud's existence, which can last for a long time. The lifetime at this stage of both tropical and especially extratropical cyclones can amount to several days up to two weeks and more. For example, in July-August 1997, a powerful extratropical cyclone from the Atlantic passed over Europe during its maturity stage. The pathway was more than $1000 \mathrm{~km}$ up to Germany and more than $1500 \mathrm{~km}$ up to the Czech Republic and Poland, where it had brought abundant and continuous precipitation and caused a devastating flood.

Calculation results of the vertical wind required to support water drops and ice crystals in equilibrium in powerful clouds (Table 2) are the obvious disproof of the representation of the role of updrafts in classical meteorology. The results correspond to an equilibrium of a segregate waterdrop in the form of a sphere under the action of gravity $\boldsymbol{m g}$ and the aerodynamic resistance force (Fig. 2a) $\boldsymbol{F}_{r e s}=c_{w} \pi \mathrm{R}^{2}$ $\left(\rho_{\text {air }} w_{\text {vert }}{ }^{2} / 2\right)$. The Archimed's buoyancy force was not accounted for due to its small value. Real ice crystals have forms corresponding to significantly higher values of the resistance force. It should be noted that $1 \mathrm{~m}^{3}$ of air in powerful clouds contains several hundreds of particles (Sedunov et al., 1991) and under this condition, vertical wind values must be significantly higher. The wind data shown in Table 2 represent the minimum limit values. The maximum limit value of the vertical wind can be evaluated if, for example, a hurricane is considered as an impenetrable cylinder (Fig. 2b) with the radius $R=200 \mathrm{~km}$ and a mass of water (vapor, 


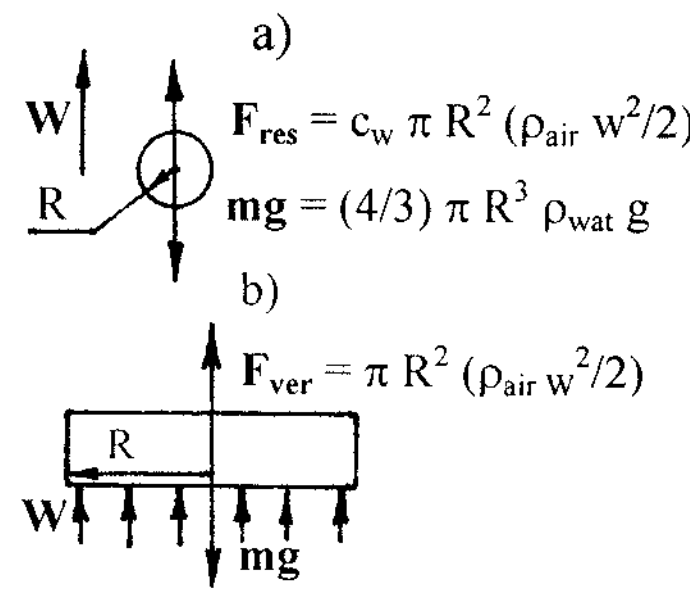

Fig. 2. Scheme of a drop (a) and a hurricane (b) equilibrium in updrafts.

drops, ice crystals) $m=10^{15} \mathrm{~kg}$ (Riehl, 1979). Equilibrium is achieved when $\boldsymbol{m} \boldsymbol{g}=\pi \mathrm{R}^{2}\left(\rho_{\text {air }} w_{\text {vert }}{ }^{2} / 2\right)$. The value of the vertical wind in this case amounts to $395 \mathrm{~m} / \mathrm{s}$. Obviously the real required vertical wind value must be higher than the minimum value and less than the maximum one, but in any case, it must be significantly higher than the vertical wind values observed in nature.

\section{Annihilation of the electric field of powerful clouds}

Tropical and extratropical cyclones and thunderclouds resulting in thunderstorms and generating tornadoes always represent conglomerations of powerful clouds which are coupled with strong electric fields. In nature, degradation of any cloud (according to the hypothesis proposed in this paper) is conditioned by the neutralization of its volume electric charge, which is realized by two different physical processes. The first is a coagulation process that is associated primarily with turbulence and the diffusion of charged particles in clouds. It should be emphasized that coagulation is the process that stipulates the infringement of a force balance and hence the intensification of precipitation and the degradation of nonthunderstorm clouds only. Action of this process continues for a long time. The second process is the lightning discharge, which ensures the neutralization of a volume electric charge in thunderclouds only. The lightning discharge represents the self-maintained discharge arising in a strong electric field (higher than $10^{6} \mathrm{~V} / \mathrm{m}$ ) in conformity with the Paschen's law. The average charge neutralized by one lightning discharge is about $30 \mathrm{C}$ and in very strong thunderstorms, it is up to $100 \mathrm{C}$ (Wormel, 1953; Bruce and Golde, 1942; Shonland, 1964; Chalmers, 1967). The effectiveness of this natural neutralization mechanism is high. So in the last mature stage, after a period of intense lightning flashes, a sudden increase in precipitation with the subsequent degradation of the thundercloud is observed (Moore et al., 1962, 1964). Herewith, the total volume electric charge
Table 3. Number of non-self-maintained discharges required to completely neutralize a volume electric charge of a powerful cloud

\begin{tabular}{cccc}
\hline$S, \mathrm{~m}^{2}$ & $E, \mathrm{~V} / \mathrm{m}$ & $Q, \mathrm{C}$ & $\mathrm{n}$ \\
\hline $2.5 \times 10^{7}$ & $10^{4}$ & 4.4 & 0.15 \\
$2.5 \times 10^{7}$ & $10^{5}$ & 44.25 & $\sim 1.5$ \\
$2.5 \times 10^{7}$ & $5 \times 10^{5}$ & 221.25 & $\sim 7.5$ \\
$2.5 \times 10^{7}$ & $10^{6}$ & 442.5 & $\sim 15.0$ \\
$10^{8}$ & $10^{4}$ & 17.7 & 0.6 \\
$10^{8}$ & $10^{5}$ & 177.0 & $\sim 6.0$ \\
$10^{8}$ & $5 \times 10^{5}$ & 885.0 & $\sim 30.0$ \\
$10^{8}$ & $10^{6}$ & 1770.0 & 59.0 \\
\hline
\end{tabular}

$S$ is an area of a square in the horizontal plane; $Q$ is the volume electric charge of a powerful cloud; $\mathrm{N}$ is a number of non-self-maintained discharges; $E=10^{6} \mathrm{~V} / \mathrm{m}$ corresponds to a thundercloud.

(negative or positive) of a single mature thundercloud cell amounts to $1400 \mathrm{C}$ (Wormel, 1953). An estimation of an electric charge value of a powerful mature thundercloud on the basis of the Gauss' law ( $\int \mathrm{Eds}=\mathrm{q} / \varepsilon_{o}$ ) at $E=10^{6} \mathrm{~V} / \mathrm{m}$ and the sizes in the horizontal plane $S=10^{4} \times 10^{4}=10^{8} \mathrm{~m}^{2}$ amounts to $Q=1770 \mathrm{C}$, which agrees with the aforementioned value. So approximately 60 lightning discharges can completely neutralize the volume electric charge of the thundercloud. However, the neutralization of even a part of a powerful cloud's volume electric charge will inevitably result in an essential reduction of an electric field, the infringement of a balance of forces acting on charged particles in the vertical direction, and the partial or complete degradation of the thundercloud and cloud clusters of tropical and extratropical cyclones. This conclusion is very important, and it allows one to formulate a highly efficient method of the effect of powerful clouds. This method consists of the following. It is necessary to create a non-self-maintained discharge by the creation of an ionized zone with electrical conductivity in the interspace between the negatively charged layer and the Earth's surface, or between the negatively charged layer and the positively charged area in a powerful cloud. The number of non-self-maintained discharges must be enough to neutralize a necessary part of a volume electric charge of a powerful cloud in order to induce its partial or complete degradation. The non-self-maintained discharges will induce the process of neutralization of a volume electric charge of powerful clouds, which, in turn, will result in a decrease in an electric potential gradient and the force $\boldsymbol{F}_{\boldsymbol{E}}$, and as a consequence, the balance of forces acting on charged particles in the vertical direction will be destroyed. Further precipitation will be vastly increased with subsequent inevitable degradation of the thundercloud. The non-self-maintained discharge, from the viewpoint of electric charge neutralization, is similar to the natural lightning discharge, and the artificial ionized 
zone created by it is an analog of the "stepped leader", which represents the initial phase of the lightning discharge. The principal distinction exists in that the lightning discharge is formed when the potential gradient in the negatively charged layer attains $10^{6} \mathrm{~V} / \mathrm{m}$ and of more, whereas the artificial ionized zone will be able to produce the non-self-maintained discharge at considerably smaller values of the electric potential gradient. This conclusion is supported by two examples. When Saturn V with Appolo 12 was launched on 14 November 1969, it induced two triggered lightning discharges (Godfrey et al., 1970) inside a powerful cloud (it should be emphasized that it was not a thundercloud). The first lightning was induced near the caudal border and the second one was induced near the upper border of the negatively charged layer of the cloud. The Saturn V was not destroyed. The same effect was observed at the launching of the Atlas-Centaur 67 on 26 March 1987; however, in this case, the rocket was wrecked (Perala et al., 1987). To ensure the development of the non-self-maintained discharge in powerful clouds, several important conditions must be fulfilled. It is obvious that recommendations with respect to these conditions can be derived from numerous studies of lightning discharges (Chalmers, 1967; Wormel, 1953; Shonland, 1964; Workman et al., 1960; Kitagawa et al., 1962). The lightning discharge is known to begin with the "stepped leader" near the caudal and upper borders of the negatively charged layer, since at these points, maximum values of an electric field potential gradient takes place, where a maximum volume electric charge density occurs. The average length of the first step of the "stepped leader" amounts to $50 \mathrm{~m}$. A channel diameter has values in the range of $0.2 / 16 \mathrm{~cm}$, and its life duration is about $1 \mu \mathrm{s}$. So an artificial ionized zone, with a form of a beam (or any possible form) and approximately the same parameters, should be created to induce the non-self-maintained discharge. It should be located above the top border or below the caudal border of the negatively charged layer. However, since the ionized zone is placed in the strong electric field $\boldsymbol{E}=10^{4}-10^{6} \mathrm{~V} / \mathrm{m}$, a triggered lightning can be initiated at some distances from the upper and caudal borders of the negatively charged layer. The most simple way of creating the focused ionized zone in the form of a beam is the launching of small solid-fuel rockets from the Earth's surface or the ocean's surface, or from airplanes or helicopters. A large number of similar solid-fuel rockets are launched annually at numerous fireworks. The exhaust gas has a rather high temperature and is weakly ionized. To increase the ionization degree of the exhaust gas, a very small amount of easily ionized material (e.g. potass) can be added in that part of a solid-fuel charge, which will form an ionized beam near the negatively charged layer. A solid-fuel rocket, with a thin metal wire following it, can be used as well. Such small rockets have been used in the lightning discharge studies (Newman, 1965; Horii, 1982; Idone et al., 1984; Eybert-Berard and Barret, 1984; Hubert et al., 1984; Horii and Sakurano, 1985; Akiyama et al., 1985). The average value of the electric charge transported by each triggered lightning discharge was 35-50 C (Newman, 1965; Hubert et al., 1984). Calculation results based on the Gauss' Law and a charge neutralized with one non-self-maintained discharge at $30 \mathrm{C}$ (Table 3) show what number of solid-fuel rockets are required to completely neutralize a volume electric charge of a powerful cloud cell, but in fact, number of rockets must be significantly less. Efficiency of the method can be increased by the delivery of a batch containing several tens of small solid-fuel charges in the area of a negatively charged layer. Hereafter, they are launched from a batch at different angles to the normal.

A more effective way of creating non-self maintained discharges in powerful clouds is the use of focused beams of electromagnetic radiation in laser and microwave frequency ranges. There are many studies in this area (e.g. MacDonald, 1966; Zarin et al., 1996). An alternative electric field in these beams creates a high enough degree of ionization with the electron density up to $n_{e}=10^{17} \mathrm{~cm}^{-3}$ (Zarin et al., 1996). It should be noted that permeability of the troposphere and especially clouds with respect to laser and microwave beams is the important problem. However, the atmosphere is known to be practically transparent for electromagnetic radiation in the range of $\lambda=10-30 \mathrm{~cm}$. For some types of lasers, the troposphere and to some extent clouds are also transparent (e.g. the florin-heavy hydrogen laser with the wavelength $\lambda=3.8 \mu \mathrm{m}$ and the chemical laser on iodine with the wavelength $\lambda=1.3 \mu \mathrm{m})$. Some attempts have been undertaken to develop lasers (e.g. infrared and ultraviolet types, Diels et al., 1997) to produce triggered lightning discharges, but these types have notably poor permeability in the troposphere and especially in clouds. Another problem is the maximum power, which is required for the generation of a focused beam. The following example shows that the average power may be quite acceptable. If one accepts the diameter of a beam $d=10 \mathrm{~cm}$ and the specific power $P_{s}=10^{2} \mathrm{Wcm}^{-2}$ (which is enough for the initiation of a microwave discharge in the air, Zarin et al., 1996), then the power of the beam will be $P_{\max }=7.85 \times 10^{3} \mathrm{~W}$. Furthermore, if the effective time of the pulse is $\tau_{e f}=10 \mu \mathrm{s}$, the pulse period-to-pulse duration ratio is $S=10^{6}$, and the efficiency of transformation and transmission of the energy is $\eta=1 \%$, then the average power will be $P_{a v}=0.785 \mathrm{~W}$.

\section{Prevention of dangerous thunderstorms and torna- does}

Tornadoes are known to be generated by very powerful thunderclouds only that occupy in height sometimes practically the whole troposphere, up to the tropopause. Herewith, Doppler radar observations show that intense rotation in tornadoes begins in the mid-troposphere at altitudes approximately $6 \mathrm{~km}$ (Snow, 1984; Davies-Jones, 1995) in the area of the negatively charged layer. Formation and intensification of a tornado, as well as the formation of its funnel, are conditioned by the action of the Electromagnetohydrodynamic (EMHD) mechanism (Krasilnikov, 1997), which emerges and develops inside, namely the negatively charged 


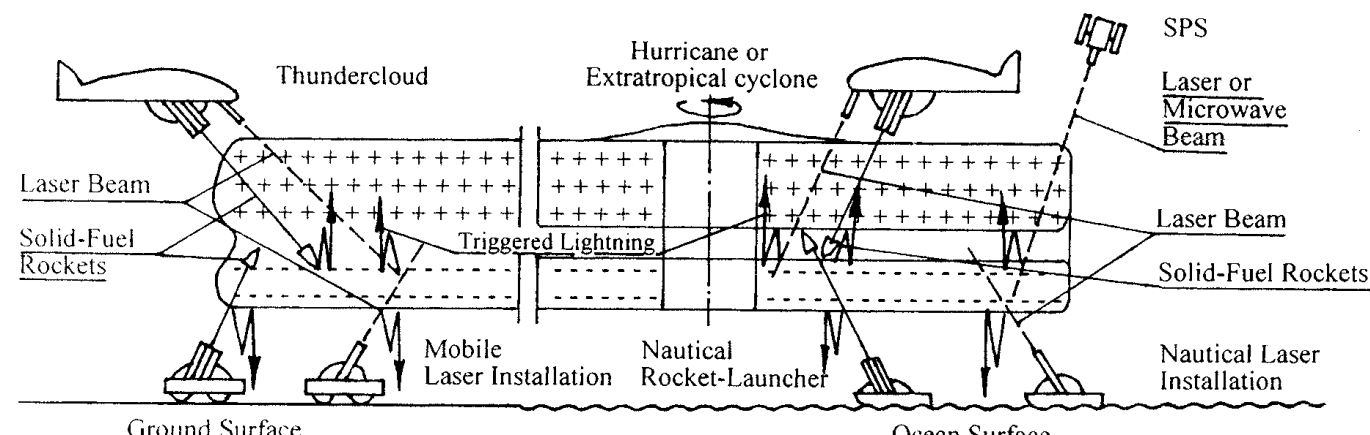

Fig. 3. Scheme showing influence means intended for suppression of powerful thunderclouds producing tornadoes (the left side) and for suppression of destructive tropical and extratropical cyclones and prevention of hurricane development and catastrophic floods (the right side).

layer. Herewith, electric and electromagnetic forces can determine these processes. But it should be emphasized that tornadoes are always generated by very powerful thunderclouds only. However, powerful thunderclouds generate dangerous thunderstorms, and they themselves represent serious danger. So about 10000 severe thunderstorms are reported in the United States each year, and the resulting damage annually amounts to $1 / 3$ billion dollars (Golden and Snow, 1991). Therefore, the effect must be directed onto powerful thunderclouds directly in order to undoubtedly prevent tornado emergence and the decrease in thundercloud power up to an innocuous level (or provide their complete degradation).

For the creation of non-self-maintained discharges in order to induce triggered lightning discharges, solid-fuel rockets or batches with many small solid-fuel charges and laser beams directed from the Earth's surface from mobile and stationary installations, or from airplanes or helicopters can be used (Fig. 3). The number of non-self-maintained discharges is determined by the size (in the horizontal plane) and power (a vertical size) of a thundercloud. For example, if the total volume negative electric charge of a powerful thundercloud amounts to $1400 \mathrm{C}$ (Wormel, 1953), and one discharge neutralizes 30 C (Newman, 1965; Hubert et al., 1984), then it will be sufficient to create $25 / 30$ non-self-maintained discharges simultaneously to ensure the complete degradation of the thundercloud, but in fact, the number must be significantly less.

\section{Tropical and extratropical cyclones}

Tropical cyclones are known to form in the narrow tropical zone. Riehl (1979) has formulated six conditions for the formation of tropical cyclones, one of the most important is in that the temperature of the ocean surface must not be less than $26 / 27^{\circ} \mathrm{C}$. Riehl has emphasized that these conditions are necessary but not sufficient conditions. Therefore, they realization is not enough for the formation and intensification of tropical cyclones and for the transition to the storm and hurricane stages. For the intensification to occur, three additional conditions are necessary. These conditions are sufficient and are formulated as follows (Krasilnikov, 1997): first, it is necessary that the initial cyclonic disturbance emerge in a powerful cumulus, containing layers of charged particles with a high volume electric charge density. The second condition is that the initial cyclonic disturbance must be localized in the middle troposphere, at an altitude where the negatively charged layer is located, since this is the very area where the EMHD mechanism is realized to a maximum extent. Third, the initial cyclonic disturbance should not be too weak (the initial tangential velocity should not be less than $15 / 20 \mathrm{~m} / \mathrm{s}$ ). The probability of the simultaneous realization of all these conditions, including the additional ones, is extremely low. Therefore, from several thousand cloud clusters existing in the inner tropical zone on average, 40/50 hurricanes and typhoons are formed annually (Riehl, 1979; McBride, 1981a, 1981b; McBride and Zehr, 1981).

The strongest winds are observed in the right frontal quadrant of cyclones, hurricanes, typhoons (Riehl, 1979), and in this part of a cyclone, non-self-maintained discharges should be created. The necessary number of these discharges depends on the power of a cloud system of a cyclone. For the initiation of triggered lightning discharges, solid-fuel rockets or batches with many small solid-fuel charges and laser beams (the most perspective means) directed from the ocean surface or from airplanes, and laser and microwave beams directed from a Space Power Station (e.g. similar to the SPS offered by Glaser (1968), but with vastly less power) can be used (Fig. 3).

Extratropical cyclones are known to form outside the tropical zone; they are formed more frequently (several thousands annually; Riehl, 1979) and have larger sizes than tropical cyclones. Therefore, attenuation or complete suppression of extratropical cyclones should be realized selectively, with a focus on only those that represent a danger as destructive storms or as possible sources of devastating floods. To influence extratropical cyclones, the same means as in the previous case should be used (Fig. 3); the influence should be directed to a powerful part of the cyclone at a distance from the coast, which is sufficient enough to provide the neces- 
sary degree of attenuation. Degradation of an electric field will stipulate abundant precipitation and degradation of cyclone clouds and hence, a significant decrease in the rotating mass of the cyclone. Ultimately, this will cause considerable decrease in the mass of water in the cyclone, a reduction of its destructive power, or complete degradation.

\section{Conclusion}

A simple and highly effective method for the prevention of destructive tropical and extratropical cyclones, hurricanes, typhoons, tornadoes, and severe thunderstorms is proposed. This method is based on the mutual consideration of multiple studies on the electric properties of clouds and the concepts adopted in traditional meteorology. It should be emphasized that it is based on using of a natural phenomenon.

The main findings of the paper ensure an opportunity for transferring the problem of the prevention of destructive hurricanes, typhoons, extratropical cyclones, tornadoes, and dangerous thunderstorms to the practical area. The upto-date technical level makes it possible to demonstrate the method presented in this paper (at least by using very simple solid-fuel rockets) immediately.

\section{References}

Akiyama, H., Ichino, K., and Horii, K.: Channel reconstruction of triggered lightning flashes with bipolar currents from thunder measurements, J. Geophys. Res., 90, 10, 674-680, 1985.

Becker, T.: The hurricane Andrew scenario, Earth Space Rev., 2, 4, 7-10, 1993.

Bruce, C. E. R. and Golde, R. H.: The lightning discharge, J. Inst. Elect. Eng., 88 (H), 487-505, 1942.

Byrne, G. J., Few, A. A., and Stewart, M. F.: Electric field measurements within a severe thunderstorm anvil., J. Geophys. Res., 94, 6297-6307, 1989.

Chalmers, J. A.: Atmospheric Electricity, 2nd ed., Pergamon, New York, 515, 1967.

Clark, J. F.: Airborne measurement of atmospheric potential gradient., J. Geophis. Res., 62, 617-628, 1957.

Davies-Jones, R.: Tornadoes, Sci. Am., 273, 2, 34-41, 1995.

Diels, J.-C., Bernstein, R., Stahlkopf, K. E., and Zhao X. M.: Lightning control with lasers, Sci. Am., 277, 2, 50-55, 1997.

Eybert-Berard, A. and Barret, L.: Triggered lightning in New Mexico, J. Geophys. Res., D 89, 2511-2521, 1984.

Glaser, P. E.: Power from the Sun, Science, 162, 856-861, 1968.

Godfrey, R., Mathews, E. R., and McDivitt, J. A.: Analysis of Appolo 12 lightning incident, NASA MSC-01540, 1970.

Golden, J. H. and Snow, J. T.: Mitigation against extreme windstorms., Rev. Geophys., 29, 477-504, 1991.

Gunn, R.: The electrical charge on precipitation at various altitudes and its relation to thunderstorms, Phys. Rev., 71, 181-186, 1947.

Gunn, R.: The free electrical charge on precipitation inside an active thunderstorm., J. Geophys. Res., 55, 171-178, 1950.

Horii, K.: Experiment of artificial lightning triggered with rocket, Mem. Fac. Eng. Nagoya Univ., Japan, 34, 77-112, 1982.
Horii, K. and Sakurano, H.: Observation of final jump of the discharge in the experiment of artificially triggered lightning, IEEE Trans. Power Appar. Syst., PAS-104, N 10, 2511-2521, 1985.

Hubert, P., Laroche, P., Eybert-Berard, A., and Barrel, L.: Triggered lightning in New Mexico, J. Geophys. Res., D 89, 2511-2521, 1984.

Idone, V. P., Orville, R. E., Hubert, P., Burret, L., and EybertBerard, A.: Correlated observations of triggered lightning flashes, J. Geophys. Res., D 89, 1385-1384, 1984.

Imianitov, I. M., Chubarina, E. V., and Shvarts, Y. M.: Electricity of Clouds, Hidrometeoizdat, St. Petersburg, Russia, 94, 1971.

Kitagawa, N., Brook, M., and Workman, E. J.: Continuing currents in cloud-to-ground lightning discharges, J. Geophys. Res., 67, 637-647, 1962.

Krasilnikov, E.: Electromagnetohydrodynamic nature of tropical cyclones, hurricanes, and tornadoes, J. Geophys. Res., 102, 13, 571-580, 1997.

MacDonald, A. D.: Microwave breakdown in gases, John Wiley and Sons, Inc., New York, 1966.

McBride, J. L.: Observational analysis of tropical cyclone formation. Part I: Basic description of data sets, J. Atmos. Sci., 38, 1117-1131, 1981a.

McBraid, J. L.: Observational analysis of tropical cyclone formation. Part III: Budget analysis, J. Atmos. Sci., 38, 1152-1166, $1981 b$.

McBride, J. L. and Zehr, R.: Observational analysis of tropical cyclone formation. Part II: Comparison of non-developing versus developing systems, J. Atmos. Sci., 38, 1132-1151, 1981.

Marshall, T. C. and Rust, W. D.: Electrical structure and updraft speeds in thunderstorms over the southern Great Plains, J. Geophys. Res., 100, 1001-1015, 1995.

Matveev, L. T.: Common Course of Meteorology, Hidrometeoizdat, St. Petersburg, Russia, 279, 1984.

Moore, C. B., Vonnegut, B., Machado, J. A., and Survilas, H. J.: Radar observations of rain gushes following overhead lightning strokes, J. Geophys. Res., 67, 207-220, 1962.

Moore, C. B., Vonnegut, B., Vrablik, E. A., and McCaig, D. A.: Gushes of rain and hail after lightning, J. Atmos. Sci., 21, 645665, 1964.

Newman, M. M.: Use of triggered lightning to study the discharge process in the channel and application to V.L.F. propagation studies, in: Problems of Atmospheric and Space Electricity, (Ed) Coronity, Elsevier, New York, 482, 1965.

Norinder, H. and Salka, O.: Mechanism of positive spark discharges with long gaps in air at atmospheric pressure, Ark. Fys., 3, 347386, 1951.

Ooyama, K. V.: On basic problems in theory and modeling of the tropical cyclone, in: Intense Atmospheric Vortices, (Ed) Bengtsson, L. and Lighthill, J., Springer-Verlag, New York, 21-34, 1982.

Perala, R. A., Collier, R. S., and Rudolif, T.: An analysis of Atlas Centaur triggered lightning conditions, Electromagnetic Applications Incorporated, EMA-87-R-49, NASA Kennedy Space Center, 1987.

Phillips, B. B. and Kinzer, G. D.: Measurements of the size and electrification of droplets in cumuliform clouds, J. Meteorol., 15, 369-374, 1958.

Riehl, H.: Climate and weather in the tropics, Academic, San Diego, Calif. USA, 611, 1979.

Sedunov, Yu. S. et al.: Atmosphere, Hidrometeoizdat, St. Petersburg, Russia, 509, 1991.

Shonland, B. F. J.: The Flight of Thunderbolts, 2nd ed., Clarendon, 
Oxford, England, 1964.

Smith, L. G.: The electric charge of raindrops., Q. J. R., Meteorol. Soc., 81, 23-47, 1955.

Snow, J. T.: The tornado, Sci. Am., 250, 4, 56-65, 1984.

Vonnegut, B.: Possible mechanism for the formation of thunderstorm electricity, Bull. Am. Meteorol. Soc., 34, 378-381, 1953.

Williams, E. R.: The tripole structure of thunderstorms, J. Geophys. Res., 94, 13, 151-167, 1989.

Workman, E. J. and Reynolds, S. E.: Electrical phenomena occurring during the freezing of dilute aqueous solutions and their possible relationship to thunderstorm electricity, Phys. Rev., 78,
254-259, 1950.

Workman, E. J., Brook, M., and Kitagawa, N.: Lightning and charge storage, J. Geophys. Res., 65, 1513-1518, 1960.

Wormel, T. W.: Atmospheric electricity: Some recent trends and problems, Q. J. R. Meteorol. Soc., 79, 3-50, 1953.

Zarin, A. S., Kuzovnikov, A. A., and Shibkov, V. M.: Freely localized microwave discharge in air, Neft i Gas, Moscow, Russia, 204, 1996.

Ziegler, C. L. and MacGorman, D. R.: Observed lightning morphology relative to modeled space charge and electric field distributions in a tornadic storm, J. Atmos. Sci., 51, 6, 833-851, 1994. 